\title{
A STUDY ON THE PRACTICAL MODEL OF PLANNED EFFECTIVE RAINFALL FOR PADDY FIELDS IN TAIWAN
}

\author{
Shi-Ming Tsai \\ Associate Professor, Institute of Regional Policy and Development, National Taitung University, 684, Sec. 1, Chung \\ Hua Road, Taitung, Taiwan 950, shiming@nttu.edu.tw \\ Shinne Chen \\ Director of Engineering Section, Agricultural Engineering Research Center, 196-1, Chung Yuan Road, Chung-Li, Taiwan \\ 320. \\ Hsin-Yi Wang \\ Ph.D. candidate, Department of Hydraulic \& Ocean Engineering, National Cheng Kung University, Tainan, Taiwan 701
}

Follow this and additional works at: https://jmstt.ntou.edu.tw/journal

Part of the Civil and Environmental Engineering Commons

\section{Recommended Citation}

Tsai, Shi-Ming; Chen, Shinne; and Wang, Hsin-Yi (2005) "A STUDY ON THE PRACTICAL MODEL OF PLANNED EFFECTIVE RAINFALL FOR PADDY FIELDS IN TAIWAN," Journal of Marine Science and Technology. Vol. 13: Iss. 2, Article 1.

DOI: $10.51400 / 2709-6998.2106$

Available at: https://jmstt.ntou.edu.tw/journal/vol13/iss2/1

This Research Article is brought to you for free and open access by Journal of Marine Science and Technology. It has been accepted for inclusion in Journal of Marine Science and Technology by an authorized editor of Journal of Marine Science and Technology. 


\title{
A STUDY ON THE PRACTICAL MODEL OF PLANNED EFFECTIVE RAINFALL FOR PADDY FIELDS IN TAIWAN
}

\author{
Shi-Ming Tsai,* Shinne Chen, ${ }^{* *}$ and Hsin-Yi Wang***
}

Key words: irrigation, effective rainfall, gate operation management.

\section{ABSTRACT}

In this study of irrigation management systems, a method has been developed for rice paddies to predict the planned effective rainfall based on gate operation management system used in the Taoyuan Irrigation Association, Taiwan. The practical model for rotational irrigation developed in this study considers the effective height of the border ridge of farm parcels in the irrigation plans of Irrigation Association in Taiwan. To estimate the planned monthly effective rainfall, the best-fit distribution of monthly effective rainfall was first determined; then the value of the 75 percent of the probability of occurrence was used for analysis. The calculated monthly effective rainfall is about 113 percent of the value used by the gate operation management. This study suggests that the high limit of effective rainfall depth can be increased from $30 \mathrm{~mm}$ to $42 \mathrm{~mm}$ to raise the planned effective rainfall.

\section{INTRODUCTION}

The estimation of effective rainfall has always been a problem in agricultural irrigation management. A precise estimate of effective rainfall is still needed not only for the planning of new irrigation projects and management of existing irrigation systems, but also for practical irrigation in the fields. Possible results of underestimating effective rainfall include the unnecessary waste of natural water resources, an increase in construction costs, and a decrease in the benefit-cost ratio of the project. Another consequence is the waste of irrigation manpower, which is useless and potentially

Paper Submitted 04/27/04, Accepted 12/10/04. Author for Correspondence: Shi-Ming Tsai. E-mail: shiming@nttu.edu.tw.

*Associate Professor, Institute of Regional Policy and Development, National Taitung University, 684, Sec. 1, Chung Hua Road, Taitung, Taiwan 950.

**Director of Engineering Section, Agricultural Engineering Research Center, 196-1, Chung Yuan Road, Chung-Li, Taiwan 320.

***Ph.D. candidate, Department of Hydraulic \& Ocean Engineering, National Cheng Kung University, Tainan, Taiwan 701. harmful to the growth of crops. If the effective rainfall is overestimated, the irrigation water application based on this value will be unable to provide enough water so as to maintain a good yield of crop; the irrigation system designed on this basis will have similar results. In addition, the designed flow of the irrigation system cannot adapt to the need for special arrangements for rotation irrigation whenever droughts occur. Therefore, it is necessary to seek a reasonable, precise, and efficient method to estimate effective rainfall. The enhancement of the utilization of natural effective rainfall will become one of the common goals of all pursuant irrigation researchers in the world.

\section{DEFINITION OF EFFECTIVE RAINFALL AND LITERATURE REVIEW}

\section{Definition of effective rainfall}

Due to different viewpoints and operation methods in irrigation management systems, the definition of effective rainfall can be classified into three categories: (1) when crops are concerned, the rainfall (any small rainfall) beneficial to the crops may be called effective rainfall; (2) for field management, with paddy fields as the main object, the decreased water intake due to rainfall may be called effective rainfall; (3) for water resource management (i.e., the Irrigation Associations), the amount of less released water due to rainfall may be called effective rainfall. The third one will be adopted as the definition of effective rainfall in this study, because the storage basin (or reservoir) may release less irrigation water due to the effective rainfall.

\section{Literature review}

In the Final Plan Report of Shinmen Reservoir Project [5], measured data from the Lin-Ko-Chuang and Ta-Chiang-Mu experimental stations were used to plot 
a correlation curve between effective rainfall and monthly rainfall for each month that continuous irrigation was applied. The monthly effective rainfall could be obtained directly from the curve by the corresponding monthly rainfall of the irrigation district. A major flaw of this method is that the experimental stations were situated in the mountain areas, far from the actual irrigation fields. Besides, the irrigation method used during the experiment was the continuous irrigation method, which is entirely different from rotational irrigation. According to effective rainfall definitions (1) \& (2), Tsao [11] treated the paddy field as a bucket to compute the daily effective rainfall based on soil, water usage, and the growing stages of crops, and evaluate the monthly planned effective rainfall for the entire paddy growth period according to the probability of occurrence. Tsao's day-by-day bookkeeping method is very contemplative; however, the cost of water in the irrigation districts in Taiwan are not charged by volume, and the irrigation operation is difficult to predict from the growing periods and the planting dates. As a result, there are significant differences between the computational method and the actual operation. Kan [6] applied the irrigation, drainage, and rainfall measuring computations to an actual paddy field with plot-to-plot irrigation in Indonesia. Nonetheless, the method used in this experiment is specific to plot-to-plot irrigation, and cannot be used for rotational irrigation in Taiwan. Chen [1] calculated the effective rainfall by using first crop period as the calculating interval. The monthly effective rainfall was added as an independent variable in computation. The monthly effective rainfall values can be directly used for probability analysis to estimate the planned effective rainfall. Effective rainfall estimates by the United States Department of Agriculture Soil Conservation Service (USDA-SCS) and the Hershfield methods [7] for either soil condition were not as accurate as the soil water balance model (SWBM) estimates for events with return periods higher than the

Table 1. Relationship among rainy days, rainfall amount and the cut-off water supply days

\begin{tabular}{ccc}
\hline Rainy days $N$ & Rainfall $\mathrm{R}(\mathrm{mm})$ & $\begin{array}{c}\text { Cut-off water supply } \\
\text { days } K \text { (day) }\end{array}$ \\
\hline \multirow{4}{*}{1 day } & $R \leq 5$ & 0 \\
& $5<R \leq 9$ & 1 \\
& $9<R \leq 30$ & $1+(R-9) / \mathrm{d}$ \\
& $30<R$ & $1+(30-9) / \mathrm{d}$ \\
\hline \multirow{3}{*}{$N$ days } & $5<\sum R \leq 9$ & 1 \\
& $9<\sum R \leq 30$ & $1+\left(\sum R-9\right) / d$ \\
& $30<\sum R$ & $1+[(30-9) / d]+N$ \\
\hline
\end{tabular}

mean annual event.

Today, Taiwan uses two methods to calculate the planned monthly effective rainfall. The first method uses the average of the monthly effective rainfall of the past five years. The second method is to calculate the fourth least value of the monthly effective rainfall for the past 20 years as the planned monthly effective rainfall.

In this study, a method to predict the planned effective rainfall based on gate operation management is developed for paddy fields. Based on rotational irrigation, a practical model can be developed by considering the effective height of the border ridge of field parcel in the irrigation plan of Taoyuan Irrigation Association in Taiwan.

\section{MODEL ESTABLISHMENT}

\section{Estimation of effective rainfall}

As this study is aiming at improving existing irrigation distribution management methods of the irrigation association of Taoyuan Main Canal, this model was designed to estimate the effective rainfall based on the gate operation principle.

The effective rainfall will be estimated according to the relationship among rainy days, rainfall amount, and the cut-off water supply days of the irrigation district of the Taoyuan Main Canal (as in Table 1).

The computation procedures are as follows: (1) Determine the cut-off days $(K)$ of water supply from rainfall characteristics using Table 1; (2) Compute the effective rainfall $(E R)$ using $E R=K \bullet d$. The effective rainfall is obtained by multiplying the cut-off days of water supply by daily irrigation requirement (d). If rainfall is smaller than or equal to $5 \mathrm{~mm}$, the effective rainfall is neglected. Multiple days of effective rainfall is to be computed by the weightings of rainfall, and the computation method is as follows [8]: a. For one day rainfall

$$
E R= \begin{cases}0 & \text { If } R \leq 5 \mathrm{~mm} \\ d & \text { If } 5<R \leq 9 \mathrm{~mm} \\ \left(1+\frac{R-9}{d}\right) d & \text { If } 9<R \leq 30 \mathrm{~mm} \\ \left(1+\frac{30-9}{d}\right) d & \text { If } R>30 \mathrm{~mm}\end{cases}
$$




$$
\begin{gathered}
E R= \begin{cases}d & \text { If } 5<\sum \leq 9 \mathrm{~mm} \\
\left(1+\frac{\sum R-9}{d}\right) d & \text { If } 9<\sum R \leq 30 \mathrm{~mm} \\
{\left[\left(1+\frac{30-9}{d}\right)+N\right] d \text { but, } E R \leq \sum R} & \text { If } \sum R>30 \mathrm{~mm}\end{cases} \\
E R_{i}=\frac{R_{i}}{\sum_{i=1}^{N} R_{i}}(E R) \\
E R_{m}=\sum_{i=1}^{30 \text { or } 31}\left(E R_{i}\right)
\end{gathered}
$$

where $E R$ : effective rainfall of single rainfall event $(\mathrm{mm}): E R_{i}$ : daily effective rainfall $(\mathrm{mm}) ; E R_{m}$ : monthly effective rainfall $(\mathrm{mm}) ; R$ : daily rainfall $(\mathrm{mm}) ; d$ : one day irrigation requirement ( $\mathrm{mm} /$ day).

The existing method of Taoyuan Irrigation Association for effective rainfall calculation is a function of daily rainfall $(R(I))$ and daily water storage depth in paddy field $(S(I))$. The daily effective rainfall $(E R(I))$ will be calculated by the following procedures:

a. For one day rainfall (let $S(I)=S(I-1)+R(I)-d)$

$E R(I)=\left\{\begin{array}{llll}0 & \text { when } R(I) \leq 5 \mathrm{~mm} & ; \text { If } S(I)<0, \text { let } S(I)=0 \\ R(I) & \text { when } 5<R(I) \leq 60 \mathrm{~mm} & ; \text { If } S(I)<0, \text { let } S(I)=0 \\ 60 & \text { when } R(I)>60 \mathrm{~mm} & \text {; If } S(I)>60, \text { let } S(I)=60 & \text { (12) }\end{array}\right.$

b. For $N$ successive rainy days (let $S(I)=S(I-1)+R(I)$ $-d)$

$$
\begin{gathered}
E R(I)=\left\{\begin{array}{lll}
R(I) & \text { when } S(I) \leq 60 \mathrm{~mm} & ; \text { If } S(I)<0, \text { let } S(I)=0 \\
R(I)-S(I)+60 & \text { when } S(I)>60 \mathrm{~mm} & ; \text { and let } S(I)=60
\end{array}\right. \\
E R_{m}=\sum_{i=1}^{30 \text { or } 31} E R(I)
\end{gathered}
$$

where $S(I-1)$ : the previous day's water storage depth in paddy field.

Theoretically, the amount of water each application in rotational irrigation should be changed so as to match with water requirement of the paddy for each period of its growth. At the same time, the percolation depth is different depending upon the type of soil in the paddy field, and thus the irrigation depth should also be changed with respect to the type of soil (as Table 2). However, these complicated changes are very difficult to standardize for practical operation, so the conserved value of $6 \mathrm{~mm} /$ day is adopted to facilitate irrigation management.

According to the monthly effective rainfall for past 20 years arranged from the largest to the smallest, the fourth least value is taken as the planned monthly effective rainfall. This is equivalent to the 80 percent probability of occurrence, which does not agree with the hydrological conditions in the existing water right registering of Taiwan. The probability of occurrence of rainfall in an average year is 75 percent, and therefore the method used to estimate effective rainfall needs to be revised. This study tries to use 20 years' monthly effective rainfall to examine the 75 percent probability of occurrence in the Normal distribution or Gamma distribution for the planned monthly effective rainfall. The Chi-Square method is used to determine the best probability distribution.

\section{Establishment of model}

In this study, the establishment of the model includes two parts. First, the daily effective rainfall is computed based on the number of days of cut-off water supply for the 20-year long daily rainfall. Then these are accumulated to yield the monthly effective rainfall. Second, the distribution pattern of this monthly effective rainfall is analyzed to find the best-fit distribution. The 75 percent probability of occurrence of this optimum distribution will be computed as the planned monthly effective rainfall. The computation flow chart is shown in Figure 1.

\section{Computation results}

\section{(1) Daily effective rainfall computation}

\begin{tabular}{|c|c|c|c|}
\hline & & \multicolumn{2}{|c|}{ Daily water depth } \\
\hline & & $\begin{array}{c}\text { Within } 30 \text { days of } \\
\text { transplant rice } \\
\text { seedings }\end{array}$ & $\begin{array}{l}\text { After } 30 \text { days of } \\
\text { transplant rice } \\
\text { seedings }\end{array}$ \\
\hline \multirow{4}{*}{ First Crop } & light clay & 7.2 & 6.0 \\
\hline & clayey soil & 7.6 & 6.4 \\
\hline & sandy clay & 8.1 & 6.7 \\
\hline & sandy soil & 10.1 & 8.4 \\
\hline \multirow{4}{*}{ Second Crop } & light clay & 7.6 & 6.4 \\
\hline & clayey soil & 8.1 & 6.7 \\
\hline & sandy clay & 8.4 & 7.0 \\
\hline & sandy soil & 10.8 & 9.0 \\
\hline
\end{tabular}

The daily effective rainfall can be computed from rainy days, amount of rainfall, and cut-off days of water supply. Table 3 is the daily effective rainfall computation from March 26 till May 12, 1994 at the Wuchuen

Table 2. One day irrigation consumption (unit: $\mathbf{m m} / \mathrm{day}$ ) 
Table 3. Daily effective rainfall calculation of Wuchuen station in 1994 (unit: mm)

\begin{tabular}{lcccccccccc}
\hline Date & $\mathbf{3 / 2 6}$ & $\mathbf{3 / 2 7}$ & $\mathbf{3 / 2 8}$ & $\mathbf{3 / 2 9}$ & $\mathbf{3 / 3 0}$ & $\mathbf{3 / 3 1}$ & $\mathbf{4 / 1}$ & $\mathbf{4 / 2}$ & $\mathbf{4 / 3}$ & $\mathbf{4 / 4}$ \\
\hline Rainfall & 1.0 & 0.0 & 0.0 & 0.0 & 0.5 & 8.0 & 0.0 & 0.0 & 0.0 & 0.0 \\
Effective rainfall & 0.0 & 0.0 & 0.0 & 0.0 & 0.4 & 5.6 & 0.0 & 0.0 & 0.0 & 0.0 \\
Date & $\mathbf{4 / 5}$ & $\mathbf{4 / 6}$ & $\mathbf{4 / 7}$ & $\mathbf{4 / 8}$ & $\mathbf{4 / 9}$ & $\mathbf{4 / 1 0}$ & $\mathbf{4 / 1 1}$ & $\mathbf{4 / 1 2}$ & $\mathbf{4 / 1 3}$ & $\mathbf{4 / 1 4}$ \\
Rainfall & 0.0 & 0.0 & 0.0 & 0.0 & 0.0 & 0.0 & 0.0 & 2.0 & 19.7 & 0.5 \\
Effective rainfall & 0.0 & 0.0 & 0.0 & 0.0 & 0.0 & 0.0 & 0.0 & 1.8 & 17.4 & 0.4 \\
Date & $\mathbf{4 / 1 5}$ & $\mathbf{4 / 1 6}$ & $\mathbf{4 / 1 7}$ & $\mathbf{4 / 1 8}$ & $\mathbf{4 / 1 9}$ & $\mathbf{4 / 2 0}$ & $\mathbf{4 / 2 1}$ & $\mathbf{4 / 2 2}$ & $\mathbf{4 / 2 3}$ & $\mathbf{4 / 2 4}$ \\
Rainfall & 3.0 & 0.0 & 0.0 & 0.0 & 0.0 & 0.0 & 0.0 & 0.0 & 0.0 & 0.0 \\
Effective rainfall & 2.6 & 0.0 & 0.0 & 0.0 & 0.0 & 0.0 & 0.0 & 0.0 & 0.0 & 0.0 \\
Date & $\mathbf{4 / 2 5}$ & $\mathbf{4 / 2 6}$ & $\mathbf{4 / 2 7}$ & $\mathbf{4 / 2 8}$ & $\mathbf{4 / 2 9}$ & $\mathbf{4 / 3 0}$ & $\mathbf{5 / 1}$ & $\mathbf{5 / 2}$ & $\mathbf{5 / 3}$ & $\mathbf{5 / 4}$ \\
Rainfall & 17.0 & 3.5 & 6.5 & 8.5 & 1.5 & 0.0 & 44.0 & 15.5 & 82.0 & 9.5 \\
Effective rainfall & 17.0 & 3.5 & 6.5 & 8.5 & 1.5 & 0.0 & 14.9 & 5.2 & 27.7 & 3.2 \\
Date & $\mathbf{5 / 5}$ & $\mathbf{5 / 6}$ & $\mathbf{5 / 7}$ & $\mathbf{5 / 8}$ & $\mathbf{5 / 9}$ & $\mathbf{5 / 1 0}$ & $\mathbf{5 / 1 1}$ & $\mathbf{5 / 1 2}$ & & \\
Rainfall & 0.0 & 2.0 & 0.0 & 0.0 & 0.0 & 58.0 & 8.5 & 0.0 & & \\
Effective rainfall & 0.0 & 0.0 & 0.0 & 0.0 & 0.0 & 34.0 & 5.0 & 0.0 & & \\
\hline
\end{tabular}

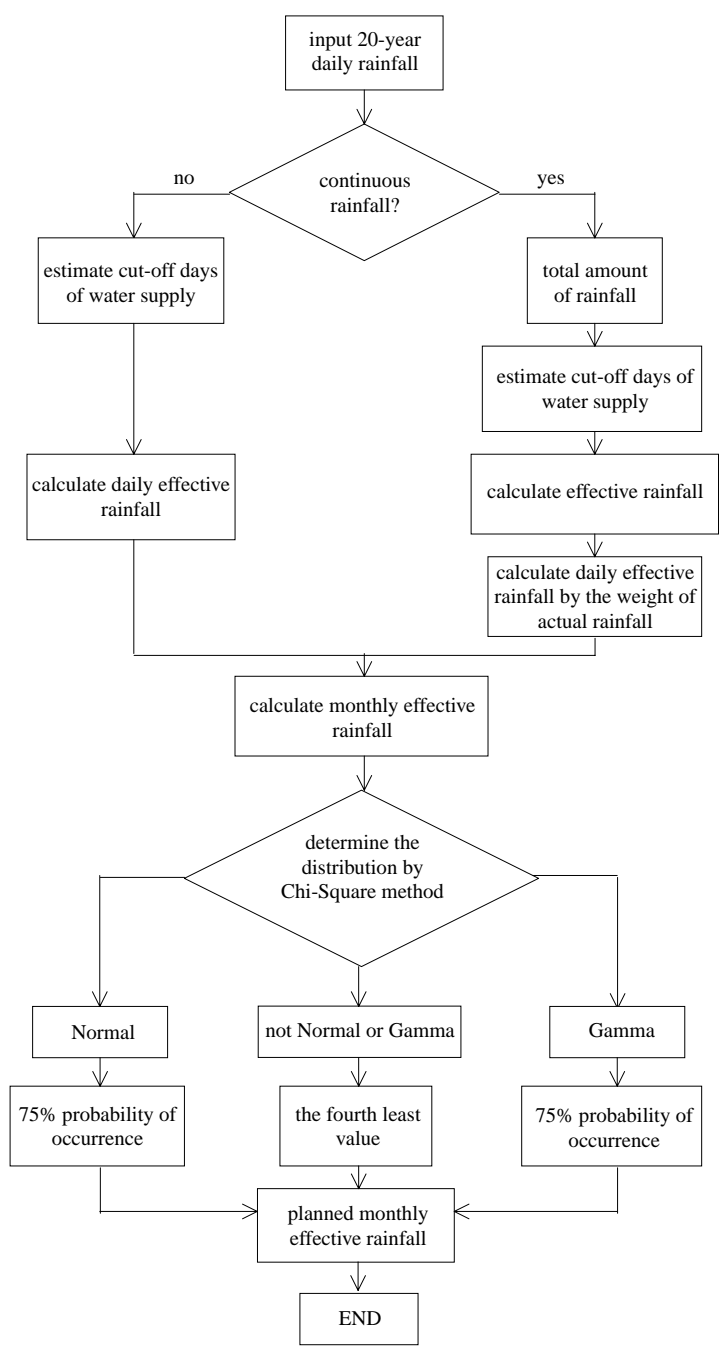

Fig. 1. Flow diagram for the planned effective rainfall computation. station. The procedure is stated as follows: (a) take a single rainy day as an example: the rainfall was $2.0 \mathrm{~mm}$ on May 6 , so the daily effective rainfall is $0.0 \mathrm{~mm}$ because it did not exceed $5.0 \mathrm{~mm}$; (b) take continuous rainfall as an example: the continuous rainfall was 37.0 $\mathrm{mm}$ from April 25 to April 29, and the effective rainfall may be computed as $57.0 \mathrm{~mm}$ because of $30<\Sigma R$. However, the effective rainfall cannot be larger than the actual rainfall, so the effective rainfall is still $37.0 \mathrm{~mm}$ during this period. The distribution of the value of daily effective rainfall is obtained according to the weight computation of actual rainfall.

\section{(2) Computation of monthly effective rainfall}

The monthly effective rainfall is computed by summing the daily effective rainfalls. For example, the monthly effective rainfall of April in 1994 is $59.2 \mathrm{~mm}$, which is calculated by summing the daily effective rainfall from April 1 to 30 as shown in Table 3. The calculated results of the monthly effective rainfalls of March to October for Wuchuen station from 1975 to 1994 are shown in Table 4. For convenience, the computed value of the monthly effective rainfall has been rounded to the nearest whole number.

\section{(3) Computation of planned monthly effective rainfall}

The planned monthly effective rainfall is calculated by using the 75 percent probability of occurrence in either the Normal distribution $(N)$ or the Gamma distribution $(G)$. The best-fit distribution of each month is determined using the Chi-Square method, with a limit of 5 percent error. The result is shown in Table 5. The 
result calculated by taking the fourth least value will be lower than other two distributions because the probability of occurrence in the former method is 80 percent, compared to the later method of 75 percent.

All the computation examples above are based on the data of Wuchuen station. Similarly, this method may also be used to compute the respective effective rainfall for the remaining nineteen stations of the Taoyuan irrigation district. The monthly effective rainfall distributions show a set of data roughly the shape of a Normal distribution or Gamma distribution among these 20 stations' data [12].

\section{MODEL VERIFICATION}

Table 4. Calculated monthly effective rainfall of Wuchuen station (unit: $\mathbf{m m}$ )

\begin{tabular}{rrrrrrrrr}
\hline Year & March & April & May & June & July & Aug. & Sept. & Oct. \\
\hline 1975 & 138 & 72 & 198 & 122 & 59 & 185 & 66 & 121 \\
1976 & 100 & 107 & 88 & 57 & 89 & 79 & 38 & 29 \\
1977 & 34 & 39 & 96 & 193 & 90 & 62 & 67 & 0 \\
1978 & 196 & 146 & 120 & 41 & 0 & 61 & 78 & 100 \\
1979 & 196 & 134 & 138 & 155 & 3 & 94 & 22 & 45 \\
1980 & 79 & 168 & 112 & 0 & 6 & 68 & 68 & 67 \\
1981 & 103 & 65 & 179 & 163 & 78 & 33 & 32 & 13 \\
1982 & 91 & 125 & 106 & 157 & 117 & 127 & 51 & 20 \\
1983 & 202 & 73 & 114 & 50 & 44 & 91 & 39 & 14 \\
1984 & 186 & 228 & 204 & 118 & 17 & 147 & 86 & 22 \\
1985 & 129 & 131 & 39 & 90 & 101 & 67 & 135 & 48 \\
1986 & 190 & 77 & 146 & 140 & 29 & 57 & 62 & 31 \\
1987 & 145 & 63 & 154 & 82 & 124 & 12 & 136 & 64 \\
1988 & 228 & 193 & 112 & 33 & 64 & 33 & 157 & 50 \\
1989 & 108 & 125 & 129 & 22 & 80 & 65 & 136 & 10 \\
1990 & 41 & 157 & 83 & 164 & 32 & 125 & 116 & 40 \\
1991 & 102 & 79 & 32 & 88 & 0 & 24 & 159 & 45 \\
1992 & 116 & 159 & 170 & 63 & 16 & 124 & 122 & 63 \\
1993 & 119 & 120 & 147 & 87 & 45 & 59 & 15 & 6 \\
1994 & 158 & 59 & 110 & 59 & 95 & 143 & 58 & 80 \\
\hline
\end{tabular}

According to the irrigation plans and the records of the work stations of the Taoyaun Irrigation Association in Taiwan $[2,3,4]$, the planned water requirement $(D)$ and the planned effective rainfall calculated by the existing method $(B)$ are both given values. The actual record of water requirement $(C)$ is the recorded value actually measured in the field by the faculty at the workstation. The actual recorded monthly effective rainfall $(A)$ can be computed as follows:

$$
A=B-C+D
$$

In order to understand the correlation between the calculated monthly effective rainfalls by the model and the recorded ones, the sample correlation coefficient and the coefficient of variation [9] will be used.

There are 8 ponds in the lateral canal \# 4 of Wuchuan workstation of the Taoyuan irrigation district. Since the ponds of 4-5, 4-6, 4-7 are close to each other, the same person collects data and manages the gate for all three ponds, the records of these three ponds are analyzed in this study. For the relationship between the model calculated and the recorded monthly effective rainfall, only the data from March to October of every year will be analyzed, because this period is the paddy growth period. In 1994 and 1996, only the second crop will be considered because the first crop was fallowed due to a shortage of water. The trend of monthly effective rainfall between the model calculated and the recorded data from 1991 to 1999 in each pond is shown in Figures 2-4, and the tendencies are almost consistent. Nevertheless, most of the recorded values of March every year tend to be higher. This is because the starting cultivating time is not the same every year, and the farmers do not follow the irrigation management policy to take the water. Hence, the model values calculated based on the gate operation principle are lower than the recorded values.

Table 6 shows the statistics between the model calculated and the recorded monthly effective rainfall for ponds 4-5, 4-6, and 4-7. For these 3 ponds, the

Table 5. Planned monthly effective rainfall calculation of Wuchuen station (unit: mm)

\begin{tabular}{ccccccccc}
\hline & March & April & May & June & July & Aug. & Sept. & Oct. \\
\hline $\begin{array}{c}\text { Normal } \\
(\mathrm{N}) 75 \%\end{array}$ & 96.6 & 82.3 & 93.2 & 57.3 & 26.0 & 51.8 & 51.3 & 22.0 \\
$\begin{array}{c}\text { Gamma } \\
(\mathrm{G}) 75 \%\end{array}$ & 93.7 & 79.6 & 90.9 & 54.2 & 23.3 & 49.0 & 48.5 & 20.0 \\
$\begin{array}{c}\text { The forth } \\
\text { least value } \\
\text { Best }\end{array}$ & 91.0 & 65.0 & 88.0 & 41.0 & 6.0 & 33.0 & 38.0 & 13.0 \\
distribution & $\mathrm{G}$ & $\mathrm{N}$ & $\mathrm{G}$ & $\mathrm{N}$ & $\mathrm{G}$ & $\mathrm{G}$ & $\mathrm{N}$ & $\mathrm{G}$ \\
\hline
\end{tabular}


Table 6. Statistics between model calculated and recorded monthly effective rainfall

\begin{tabular}{cccccc}
\hline \multicolumn{2}{c}{ Average $(\mathrm{mm})$} & $\mathrm{Se}$ & cov\% & $\mathrm{r}$ \\
\hline & Recorded & Calculated & $\begin{array}{c}\text { Standard } \\
\text { deviation }\end{array}$ & $\begin{array}{c}\text { Variation } \\
\text { coefficient }\end{array}$ & $\begin{array}{c}\text { Correlation } \\
\text { coefficient }\end{array}$ \\
\hline Pond 4-5 & 102.68 & 82.27 & 31.32 & $29.90 \%$ & 0.68 \\
Pond 4-6 & 117.49 & 86.51 & 35.99 & $31.60 \%$ & 0.69 \\
Pond 4-7 & 123.59 & 82.90 & 32.67 & $25.40 \%$ & 0.69 \\
3 ponds & 114.47 & 83.55 & 34.78 & $30.00 \%$ & 0.67 \\
\hline
\end{tabular}



Fig. 2. Trend of monthly effective rainfall of pond 4-5.



Fig. 3. Trend of monthly effective rainfall of pond 4-6.

coefficient of variation is 30 percent and the correlation coefficient is 0.67 . Therefore, the monthly effective rainfall calculated using this model is acceptable.

Figure 5 shows the relationship between the calculations using this model $\left(x_{i}\right)$ and the recorded values $\left(y_{i}\right)$ of monthly effective rainfall of the 3 ponds. The regres-

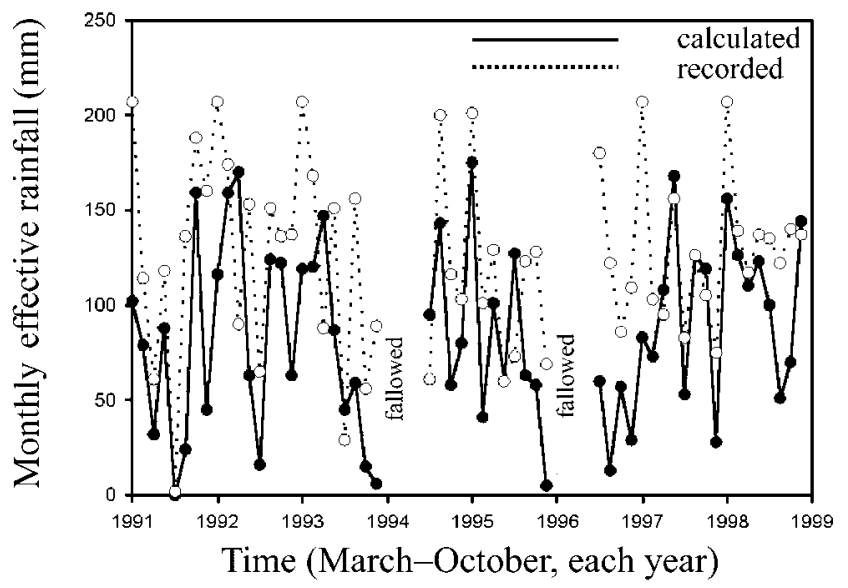

Fig. 4. Trend of monthly effective rainfall of pond 4-7.

sion line fitted to this data shows a linear relationship described with the line $y_{i}=0.65 x_{i}+61.44$ with a confidence interval of 68.5 percent. The fact that the model calculated monthly effective rainfall tends to be smaller indicates that the effective rainfall of model calculated is apparently underestimated.

Figure 6(a) shows the relationship among the planned monthly effective rainfalls computed by (1) the fourth least value method during 20 years recently, (2) 75 percent probability of occurrence using the Normal distribution method, and (3) 75 percent probability of occurrence using the Gamma distribution method, respectively. The first method has customarily been adopted as the empirical formula for years by Irrigation Associations in Taiwan. However, the results indicate that the use of the 75 percent probability of occurrence between Normal and Gamma distribution yield more accurate results. The planned monthly effective rainfall calculated by the fourth least value method is lower with a probability of occurrence of 80 percent. However, using the fifth least value, with a 75 percent probability of occurrence, the results are very close to the values calculated using Normal and Gamma distributions with the same probability of occurrence [Figure 6(b)]. 


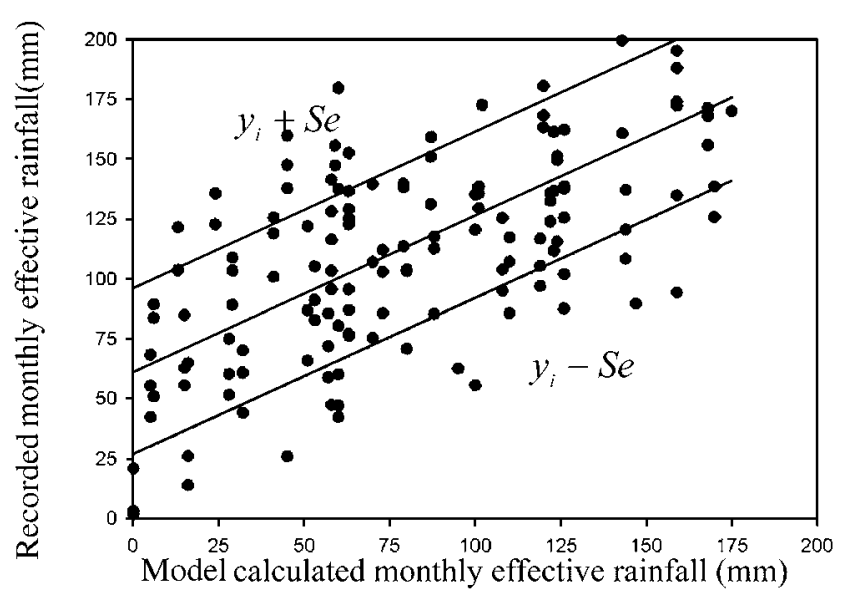

Fig. 5. Relationship between model calculated and recorded monthly effective rainfall.

\section{MODEL MODIFICATION}

The effective rainfall calculated by the model, which is based on the gate operation principle, is always lower than the recorded values. In order to unify the gate operation method with the existing computations, this study tries to modify this model by considering the effective height of border ridge and the ponding depth of paddy field.

From the gate operation principle, the original parameter of $30 \mathrm{~mm}$ is presumed to be the upper limit of the paddy field, which is allowed to hold the effective rainfall. The Kaohsiung Irrigation Association, has an effective height about $60 \mathrm{~mm}$ [10]. Chianan Irrigation Association has a minimum ponding depth of $20 \mathrm{~mm}$ [11]. The depth to hold the effective rainfall will be the effective height of border ridge subtracted by the ponding depth in paddy field. This parameter of $30 \mathrm{~mm}$ seems to be too low; therefore, a field survey is carried out in this study in order to adjust the basis of $30 \mathrm{~mm}$ parameter.

The effective height of the border ridge and the ponding depth of paddy fields are both lowest during the tilling stage. The result of a field survey by Wang [12] showed that more than 95 percent of the effective height of border ridges are higher than $60 \mathrm{~mm}$ in 30 blocks of paddy fields, and the average ponding depths are 15 $\mathrm{mm}$. Thus, the irrigation district of these 3 ponds can provide $45 \mathrm{~mm}$ to hold effective rainfall. Therefore, the effective height of the border ridge can be augmented.

Taking light clay paddy field conditions as an example, the 6 days field water requirement is irrigated on the first day by using the rotational irrigation method. That means there is $36 \mathrm{~mm}$ of water in the paddy field, and $24 \mathrm{~mm}$ effective rainfall space. The water depth of

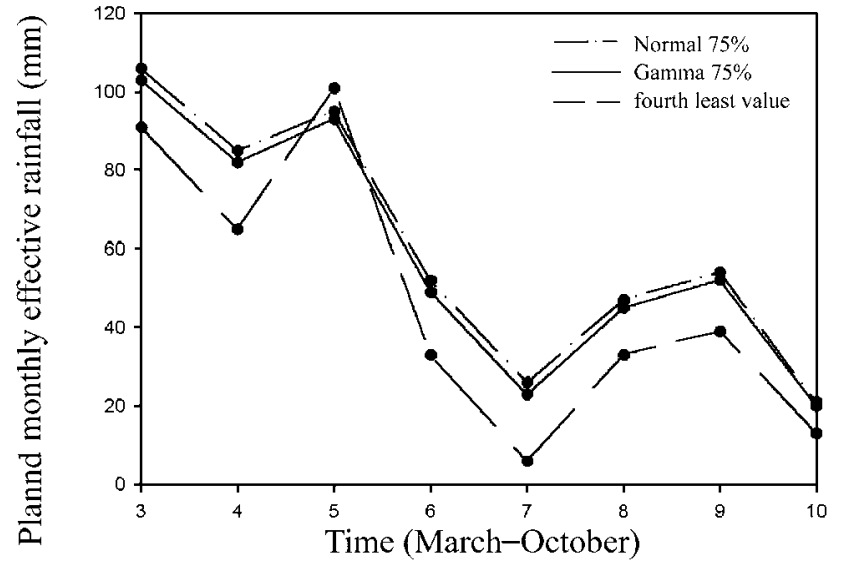

(a)

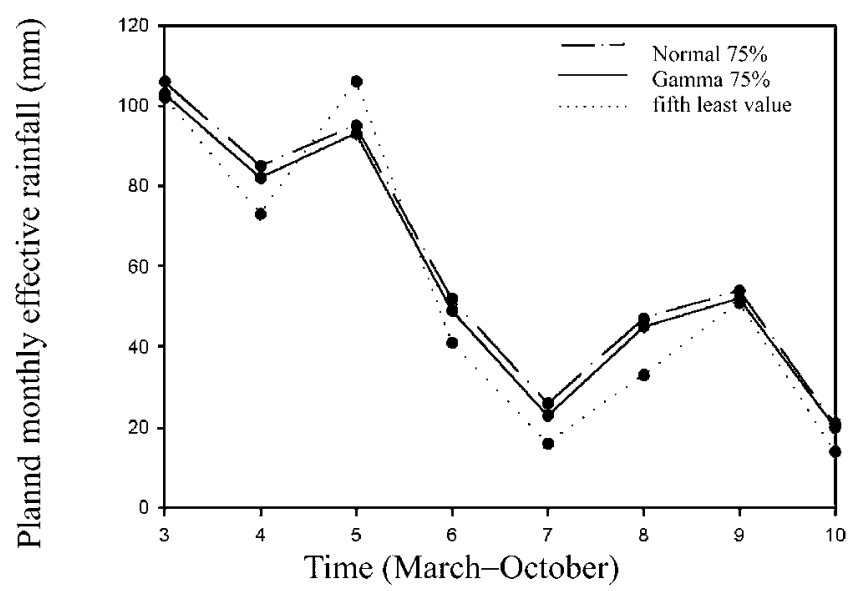

(b)

Fig. 6. Relationship among different calculated models of planned effective rainfall in 1998.

the paddy field will be zero after 6 days, i.e., there is a $60 \mathrm{~mm}$ space to hold the effective rainfall. Therefore, the space to hold the effective rainfall will be $(24+60) /$ $2=42 \mathrm{~mm}$ on average. According to the field survey, the space allowable to hold the effective rainfall is about $45 \mathrm{~mm}$, which does not differ too much with the theoretical result. This study suggests an adjustment from $30 \mathrm{~mm}$ to $42 \mathrm{~mm}$ for the effective height of the border ridge.

Three models are used in this study. They are: (1) calculated by the gate operation principle model using $30 \mathrm{~mm}$ limit of effective height (Model I), (2) calculated by the $42 \mathrm{~mm}$ high limit of effective height of the modified model (Model II), and (3) calculated by the existing method of Taoyuan Irrigation Association using equations (10)-(15) (Model III). Table 7 shows the correlation between recorded and calculated average monthly effective rainfall of each model. The lower 
correlation coefficients of these three models are due to the inconsistency of irrigation practice and the irrigation plans. The irrigation plan is based on the rotational irrigation method, whereas the method adopted by the Taoyuan Irrigation Association is continuous irrigation. Excepting this, the correlation coefficient of Model II is lower than that of Model I because the gate operation is being managed under the conditions of Model I. Because the parameter of Model I has inexplicable counterparts, the modified model(or Model II) is recommended.

A comparison of the 3 models' calculations of average monthly effective rainfall from 1991 to 1998 is shown in Table 8 . Based on the calculated value of $100 \%$ at Model I, the average monthly effective rainfall

Table 7. Correlation coefficients for recorded and calculated values

\begin{tabular}{cccc}
\hline & Pond 4-5 & Pond 4-6 & Pond 4-7 \\
\hline Model I & 0.563 & 0.536 & 0.540 \\
Model II & $\mathbf{0 . 5 4 6}$ & $\mathbf{0 . 5 2 2}$ & $\mathbf{0 . 5 4 5}$ \\
Model III & 0.508 & 0.486 & 0.533 \\
\hline
\end{tabular}

calculated by Model II and Model III are $112.6 \%$ and $123.5 \%$. The effective rainfall is overestimated for Model III because of the inconsistency between the effective rainfall estimation method and the gate operation management method. However, the average monthly effective rainfall in this modified model (Model II) is increased by about $13 \%$. Hence this modified model to the Taoyuan Irrigation Association for the reference basis on gate operation is recommended.

Figures 7 to 9 show the trend of monthly effective rainfall between the modified model computation and recorded data in each pond from 1991 to 1999 . It shows that the tendencies are consistent.

Table 9 and Figure 10 show the correlation between calculations using the modified model and recorded monthly effective rainfall for ponds 4-5, 4-6, 47. Figure 10 indicates that the regression equation is $y_{i}$ $=0.53 x_{i}+64.69$ and the confidence interval contains 68.5 percent of the data. Based on Table 9 and Figure 10 , the standard deviation of the modified model is smaller compared to computations of the previous model. Hence, the modified model is more precise and reasonable. Furthermore, the average monthly effective rainfall calculated by this modified model is in-

Table 8. Comparison of average monthly effective rainfall from 1991 to 1998 among 3 models

\begin{tabular}{cccccccccc}
\hline & March & April & May & June & July & Aug. & Sept. & Oct. & Average \\
\hline Model I & 125 & 100 & 111 & 98 & 62 & 75 & 82 & 50 & 87.9 \\
& $100.0 \%$ & $100.0 \%$ & $100.0 \%$ & $100.0 \%$ & $100.0 \%$ & $100.0 \%$ & $100.0 \%$ & $100.0 \%$ & $100.0 \%$ \\
Model II & 139 & 115 & 122 & 112 & 68 & 86 & 94 & 56 & 99.0 \\
& $11.2 \%$ & $115.0 \%$ & $109.9 \%$ & $114.3 \%$ & $109.7 \%$ & $114.7 \%$ & $114.6 \%$ & $112.0 \%$ & $112.6 \%$ \\
Model III & 144 & 123 & 129 & 118 & 81 & 106 & 104 & 64 & 108.6 \\
& $115.2 \%$ & $123.0 \%$ & $116.2 \%$ & $120.4 \%$ & $130.6 \%$ & $141.3 \%$ & $126.8 \%$ & $128.0 \%$ & $123.5 \%$ \\
\hline
\end{tabular}



Time (March-October, each year)

Fig. 7. Trend of modified model calculated monthly effective rainfall of pond 4-5.

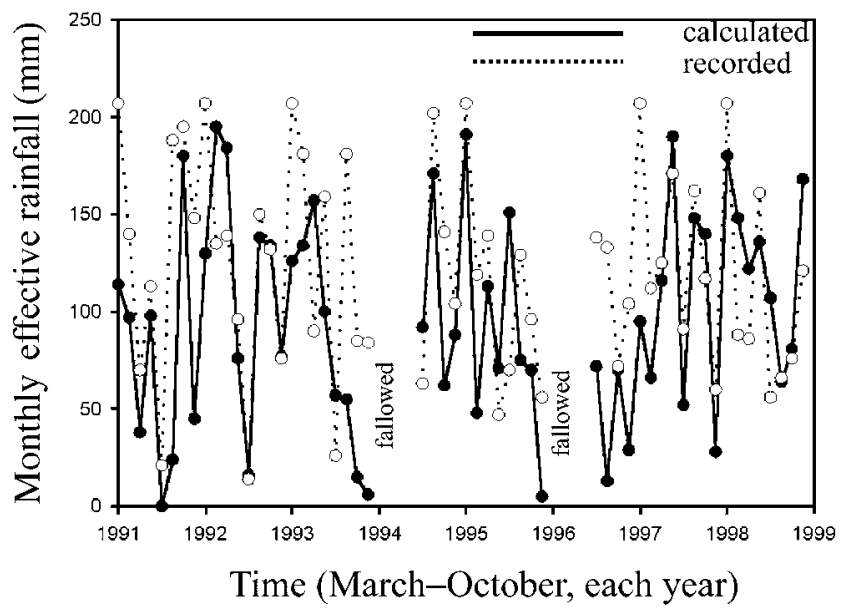

Fig. 8. Trend of modified model calculated monthly effective rainfall of pond 4-6. 


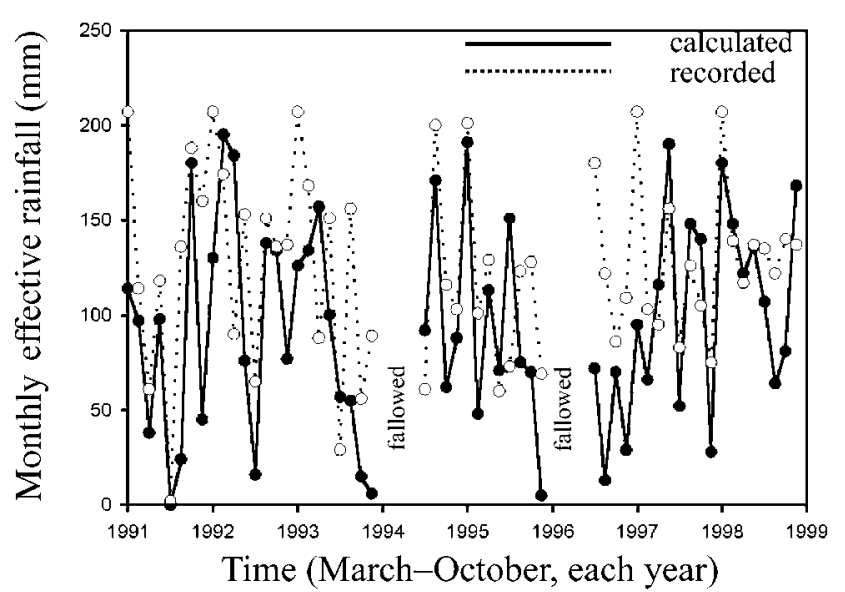

Fig. 9. Trend of modified model calculated monthly effective rainfall of pond 4-7.



Fig. 10. Relationships between modified model calculated and recorded monthly effective rainfall.

Table 9. Relation between modified model calculations and recorded monthly effective rainfall

\begin{tabular}{cccccc}
\hline & \multicolumn{2}{c}{ Average $(\mathrm{mm})$} & $\mathrm{Se}$ & cov\% & $\mathrm{r}$ \\
\hline & Recorded & Calculated & $\begin{array}{c}\text { Standard } \\
\text { deviation }\end{array}$ & $\begin{array}{c}\text { Variation } \\
\text { coefficient }\end{array}$ & $\begin{array}{c}\text { Correlation } \\
\text { coefficient }\end{array}$ \\
\hline Pond 4-5 & 102.68 & 92.84 & 31.29 & $30.50 \%$ & 0.69 \\
Pond 4-6 & 117.49 & 97.46 & 33.23 & $28.30 \%$ & 0.66 \\
Pond 4-7 & 123.59 & 93.06 & 31.20 & $25.20 \%$ & 0.69 \\
3 ponds & 114.47 & 94.40 & 32.83 & $28.70 \%$ & 0.67 \\
\hline
\end{tabular}

creased by about 13 percent. Consequently, the rate of utilization of rainfall would be raised.

\section{CONCLUSION}

(1) The estimation of effective rainfall based on the gate operation management of Taoyuan Irrigation Association in Taiwan the cut-off days of water supply is simple and practical. This method can be applied to small paddy field areas with irrigation systems based on the previous irrigation plan to distribute the water by common operation only, especially for irrigation systems with water storage ponds.

(2) When estimating the planned monthly effective rainfall, the Chi-Square method should be used to decide the best-fit probability distribution. The planned monthly effective rainfall is obtained by the $75 \%$ probability of occurrence of this optimum distribution. In other words, if the result fits either the Normal or Gamma distribution, the planned monthly effective rainfall is calculated by using the 75 percent probability occurrence of the distribution. Otherwise, the fourth least value method is adopted.
(3) The modified model considers the effective height of the paddy field border ridge and the ponding depth of the paddy field under rotational irrigation. The monthly effective rainfall calculated by this model has 13 percent more monthly effective rainfall compared to the computed value by the gate operation management as used in Taoyuan Irrigation Association, Taiwan.

(4) The effective height of border ridge is suggested to be $42 \mathrm{~mm}$ for effective rainfall calculations.

\section{REFERENCES}

1. Chen, S., "Estimation of Effective Rainfall," Chin. Soc. Agr. Eng., Vol. 25, No. 5, pp. 17-24 (1979).

2. Chen, S., Takasu, T., and Komarura, M., "Irrigation Water Management of Taoyuan District in Taiwan," $J$. Jpn. Soc. Irrig., Drain. Reclam. Eng., Vol. 54, No. 10, pp. 921-927 (1986).

3. Chen, S., Takasu, T., and Komarura, M., "Discussion of Effective Rainfall for Irrigation Plan of Taoyuan District in Taiwan," J. Jpn. Soc. Irrig., Drain. Reclam. Eng., Vol. 56, No. 8, pp. 751-758 (1988).

4. Chin, K. (Chen, S.), Takasu, T., and Komarura, M., 
"Study on the Practical of Effective Rainfall and Reasoning Method at Taoyuan Irrigation Area in Taiwan," $J$. Agr. Sci., Vol. 32, No. 2, pp. 151-163 (1987).

5. Definite Plan Report of Shihmen Reservoir Project, Shihmen Reservoir Design Committee, Ministry of Economic Affairs (1955)

6. Kan, C.E., Analysis and Research of Water Supply by Irrigation System (Research Report No. 334), Department of Agricultural Engineering, National Taiwan University, Taipei, Taiwan (1979).

7. Patwardhan, A.V., Nieber, J.L., and Eldon, L.J., "Effective Rainfall Estimation Methods," J. Irrig. Drain. EASCE, Vol. 116, No. 2, pp.182-193 (1990).

8. Tsai, S.M., Chen, S., and Wang, H.Y., "Discussion on Effective Rainfall and Its Application in Taoyuan Main Canal Irrigation Area," Proceedings of the $9^{\text {th }}$ Hydraulic Engineering Conference, D131-137 (1998).
9. Tsai, S.M., Chen, S., and Wang, H.Y., "Reliability Applied to Effective Rainfall for Irrigation," Proceedings of 1998 Agricultural Engineering Conference, pp. 361-367 (1998).

10. Tsao, I.S., A Study on the Simulation and Computation of Effective Rainfall with Results of Application in Southern Taiwan (AE-I Report No. 17), Department of Agricultural Engineering, National Taiwan University (1973).

11. Tsao, I.S., "A Study on the Calculation and Estimation of Effective Rainfall on Paddy Field by Using Electronic Computer," J. Taiwan Water Cons., Vol. 19, No. 2, pp. 7-29 (1971).

12. Wang, H.Y., "The Study on Practical Model of Effective Rainfall with Its Application in Taoyuan Main Canal Irrigation Area," Master Thesis, Department of Civil Engineering, Chung-Yuan University, Chung-Li, Taiwan (1999). 